\title{
¿PLATA O PLOMO? LA SOCIEDAD COLOMBIANA EN EL UNIVERSO NARCOS
}

\author{
Esteban Alejandro SARAVIA GEDES
}

Universidad de Alicante

\section{RESUMEN}

La ficción televisiva Narcos (2015), ambientada en la Colombia de finales de los 80 y mediados de los 90, ha sido uno de los grandes éxitos de la plataforma Netflix. Esto ha generado un gran interés por el mundo de los narcotraficantes medellinenses y caleños. A su vez, los productores de la serie han creado toda una representación de la sociedad colombiana integrada en un guion que relata la guerra del Estado colombiano y la DEA contra capos como Pablo Escobar o los hermanos Rodríguez Orejuela, pasando por el conflicto armado entre guerrillas comunistas como las FARC y de extrema derecha como los Autodefensas, la alta sociedad de Cali o las chabolas de Medellín. El objetivo de este artículo es analizar la representación que se hace de la Colombia de los narcos y distinguir el rigor histórico del romanticismo característico de las ficciones televisivas.

Palabras clave: Narcos, Colombia, televisión, sociedad, narcotráfico, América Latina

\section{ABSTRACT}

The TV show Narcos (2015), set in Colombia in the late 80s and early 90s, has been one of the great successes of the Netflix streaming platform. This has generated a great interest in the world of drug dealers of the Medellin and Cali cartels. In turn, the producers of the series have created a whole repsentation of Colombian society; all in a script that narrates the war of the colombian State and the DEA against druglords like Pablo Escobar or the Rodriguez Orejuela brothers, passing trough communist and far-right guerrilla's like Farc or the AAC, the high society of Cali or the shacks of Medellin. The objective of this paper is to analyze the representation that is made of the Colombia of the drug traffickers and to distinguish the historical rigor form the television fictions characteristic romanticism.

Keywords: Narcos, Colombia, television, society, drugdealing, Latin America 


\section{INTRODUCCIÓN: LA PROBLEMÁTICA ‘NARCO’}

El narcotráfico, y en concreto el de cocaína, ha sido (y sigue siendo) uno de los grandes mercados criminales en América Latina. Siguiendo a Ávila, un mercado ilegal se crea cuando existe una demanda efectiva y potencial insatisfecha de un determinado producto que ha sido prohibido por ser muy perjudicial para la población. Esta demanda es cubierta por una serie de actores que se colocan al margen de la legalidad, evadiendo la justicia a través de diversos mecanismos para controlar y producir dichos bienes ilegales (AA.VV., 2013: 137).

El narcotráfico es un desafío de enorme dificultad para los Estados, no sólo por los estragos que produce en la salud pública, sino también porque la influencia de los 'padrinos' de la droga llega a corromper las entrañas mismas del sistema (Cadena Montenegro, 2010: 46), ya sea con dinero (sobornos) o recurriendo al terror (secuestros, asesinatos, amenazas, etc.).

Entre las razones fundamentales para analizar el narcotráfico, Daniel Pontón (2013: 136) señala tres:

- Sustento vital de redes y actividades criminales complejas (blanqueo de dinero, secuestro de personas, red de laboratorios, rutas de transporte de la cocaína, etc.).

- Los problemas sociales (deterioro social y económico de la población) derivados de la venta y consumo de cocaína son causa indirecta del nacimiento de nuevas actividades ilegales que dependen de la actividad 'narco'.

- El narcotráfico proporciona servicio a otras actividades delictivas, consiguiendo importantes ventajas frente a otras economías criminales.

El tráfico internacional de cocaína supone el principal motor financiero de las mayores organizaciones criminales a nivel global, y según cálculos de la ONUDD del año 2005 esta actividad movía alrededor de 320.000 millones de dólares anuales, diez veces más que la segunda más rentable: el tráfico de personas. Históricamente, los dos grandes focos del narcotráfico en Latinoamérica han sido México y Colombia, países en los que han surgido ya legendarias organizaciones criminales como los carteles de Medellín, Cali, Norte del Valle, Guadalajara, Juárez... todas ellas capaces de producir y exportar incontables toneladas de cocaína principalmente a Europa y los Estados Unidos. De hecho, de acuerdo con un informe de la UNODC del año 2012, Estados Unidos sigue siendo el principal consumidor de drogas a nivel mundial, incluso hasta nuestros días. América del Norte consume un $40 \%$ de la cocaína mundial, correspondiendo un $30,8 \%$ a los Estados Unidos, lo que explica por qué este país es un suculento objetivo para los carteles de la droga. Pese a todo, las toneladas totales exportadas a suelo estadounidense se han reducido de las 267 toneladas métricas en 1998 hasta las 165 en 2008, tendencia que se ha reproducido en el consumo del resto del mundo (Pontón, 2013: 140). Aun así, continúa siendo la actividad criminal más grande del mundo, capaz de desestabilizar países enteros y de movilizar gigantescas cantidades de dinero.

Perú y Bolivia son los dos principales productores de hoja de coca del mundo. Durante todo el siglo XX una pequeñísima parte de estas hojas eran trituradas y convertidas en cocaína para su venta ilegal, pero el tráfico de esta sustancia no se convertiría en la gran actividad criminal que es hoy día hasta la década de 1970 cuando el consumo empieza a dispararse en los Estados Unidos. Este aumento del consumo puede explicarse en la nueva juventud de los setenta, imbuida en una mentalidad competitiva que le hizo despreciar los alucinógenos (consumidos de forma masiva en la década anterior) en favor de estimulantes 
como la propia cocaína. Colombia no era, en principio, un país productor, pero los enormes beneficios de la cocaína respecto a la marihuana (producto que se exportaba en gran cantidad desde Colombia) hizo que muchos traficantes de esta última cambiasen de negocio, por lo que las rutas preestablecidas para la venta de marihuana se mantuvieron, pero esta vez para exportar cocaína. Así, Colombia, país andino con una población indígena empobrecida dispuesta a trabajar en los cultivos de planta de coca, se convirtió rápidamente en el primer exportador mundial de esta droga (Sevilla Soler, 1992: 735-736).

\section{EL NARCOTRÁFICO LATINOAMERICANO EN LA FICCIÓN}

Con todos los datos analizados previamente, no es de extrañar que el narcotráfico se haya convertido en una temática muy popular en el mundo audiovisual. Como ejemplos podemos citar la cinta El precio del poder (1983). Dirigida por Brian de Palma y protagonizada por Al Pacino, narra la historia de un inmigrante cubano que, partiendo desde los bajos fondos de Miami, consigue convertirse en el narcotraficante más poderoso de la ciudad. En su periplo se topa con el ficticio Cártel Boliviano de Alejandro Sosa (Paul Shenar), primero socio y posteriormente enemigo del protagonista Tony Montana. Años más tarde Michael Douglas y Benicio del Toro protagonizan Traffic (2000), dirigida por Steven Soderbergh, filme que narra las experiencias de Robert Wakefield como supervisor de las operaciones de la DEA en México a la vez que intenta lidiar con una hija cocainómana.

Sobre Colombia, principal punto de distribución del tráfico de la cocaína mundial entre los años ochenta y mediados de los noventa, la mayoría de producciones pusieron el foco en el Cartel de Medellín y en menor medida en el de Cali. La figura de Pablo Emilio Escobar Gaviria, líder del cartel medellinense y su imperio del narcotráfico suscitaron gran interés en el mundo audiovisual a partir del año 2000. Se manifestó a través de numerosos filmes documentales que pretendían arrojar algo de luz acerca de la vida privada de 'El Patrón'. ¿Cómo era en el trato personal un hombre que sembró el terror en Colombia entre finales de los $80^{\prime}$ y principios de los 90’? A esta pregunta intentó responder el documental Los archivos privados de Pablo Escobar (2000), uno de los primeros grandes trabajos de investigación que fue emitido en televisión acerca de la influencia y poder que llegó a alcanzar el capo medellinense. Le siguieron otros como Pablo: ángel o demonio (2007), The King of Coke (2007), Pablo Escobar, El terror de Colombia (2008) y Pecados de mi Padre (2009), documental este último que recoge el testimonio de Sebastián Marroquín, hijo de Escobar quien tuvo que cambiar su identidad para desmarcarse de su pasado familiar, y que ofrece una interesante reflexión acerca de la vida personal del capo y sobre la reconciliación entre las familias de los verdugos y las víctimas.

En el mundo de la ficción la figura de Escobar saltó al primer plano gracias a la célebre serie colombiana Pablo Escobar: El Patrón del Mal (2012), dirigida por Laura Mora Ortega y Carlos Moreno y protagonizada por Andrés Parra. A lo largo de 113 episodios el drama de la cadena Caracol TV narra la vida de Escobar desde sus inicios como un joven contrabandista, pasando por el ascenso y caída de su imperio criminal, hasta su muerte a manos de la policía colombiana. Esta producción tuvo un gran éxito no sólo a nivel nacional, sino también internacional ${ }^{1}$, gracias sobre todo a la forma en la que retrató la vida personal del

1 Información extraía del sitio web de La Nación, disponible en: https://www.lanacion.com.ar/1657577escobar-el-patron-de-mal-las-claves-del-exito-de-la-serie-del-momento. [Fecha de consulta: 03/05/18]. 
narcoterrorista más buscado de Latinoamérica, intentando recrear no sólo su personalidad despiadada y cruel, sino además su lado más humano. El escritor Mario Vargas Llosa, en una columna de opinión del periódico El País, reflexionaba lo siguiente tras visionar la serie:

Lo que produce escalofríos viendo esta serie es la impresión que deja en el espectador de que, si el poder y la fortuna de que disponía no lo hubieran empujado en los años finales de su vida a excesos patológicos y a malquistarse con sus propios socios, a los que extorsionaba y mandaba asesinar, y se hubiera resignado a un papel menos histriónico y exhibicionista, Pablo Escobar podría haber llegado a ser, hoy, presidente de Colombia, o, acaso, el dueño en la sombra de ese país. Lo perdió la soberbia, el creerse todopoderoso, el generar tantos enemigos en su propio entorno y producir tanto miedo y terror con los asesinatos colectivos de los coches bomba que hacía explotar en las ciudades a las horas punta para que el Estado se sometiera a sus consignas, que sus propios compinches se apandillaran contra él y fueran un factor principalísimo en su decadencia y final (Vargas Llosa, 2013).

En el cine la figura de Escobar ha sido interpretado por Benicio del Toro en Escobar: Paradise Lost (2014) y por Javier Bardem en Loving Pablo (2017), dos películas que no se centraban tanto en la figura de 'El Patrón' como sí en algunos de sus allegados y allegadas más próximos: la primera es un relato ficticio acerca de la pareja de su hija y la segunda nos enseña la perspectiva de la periodista Virginia Vallejo (interpretada por Penélope Cruz), amante de Escobar, sobre su relación con el 'Robin Hood paisa'2. Estas nuevas perspectivas a la hora de abordar la vida del capo medellinense demuestran la fascinación que despierta en el mundo audiovisual la temática del narcotráfico en general y la figura de Pablo Escobar en particular.

\section{LA COLOMBIA DE NARCOS}

Pero si hay una producción que puso las historias de narcos colombianos en el primer plano audiovisual esa es sin duda la ficción televisiva de Netflix Narcos (2015)³, creada por Chris Brancato, Carlo Bernard, Doug Miro y Paul Ericksen. Consta hasta el momento de tres temporadas, y una cuarta que se estrenará a mediados del 2018. En sus tres primeras entregas la serie nos narra la lucha del gobierno colombiano y la DEA frente a los peligrosos carteles de Medellín y Cali. Los personajes principales son Javier Peña (interpretado por Pedro Pascal) y Steve Murphy (Boyd Holbrook), dos agentes norteamericanos a través de cuya perspectiva se narra la verdadera guerra que se libra en el país sudamericano entre el gobierno y los narcotraficantes, encarnados por Wagner Moura (Pablo Escobar), Damián Alcázar (Gilberto Rodríguez), Francisco Denis (Miguel Rodríguez), Alberto Amman ('Pacho' Herrera) y Pepe Rapazote (José 'Chepe' Santacruz).

2 Este apodo le fue conferido a Escobar en un polémico artículo de la Revista Semana en su edición número 50, en abril de 1983.

3 La ficha técnica de la obra ha sido extraída del portal IMDb, disponible en: https://www.imdb.com/title/ tt2707408/. [Fecha de consulta: 03/05/18]. 
Para la construcción de su relato, la historia entremezcla imágenes de archivo con sucesos ficticios, en una línea cronológica que abarca desde la década de los setenta hasta 1995. El escenario principal de las tres primeras temporadas es Colombia, principalmente las ciudades de Medellín y Cali.

En este trabajo nos centraremos en la representación que hace la ficción de la sociedad colombiana.

\section{¿UN (NARCO)ESTADO FALLIDO?}

A lo largo de las tres primeras temporadas de Narcos se nos presenta una Colombia que cumple algunos de los requisitos para considerarlo Estado fallido, siguiendo las consignas de los internacionalistas Herman y Rartner. Para dichos expertos esta situación se alcanza cuando un país es incapaz de proporcionar protección a sus ciudadanos, representando una amenaza para Estados vecinos, presenta una fuerte inestabilidad política y económica, conflictos internos, etc. (Zapata Callejas, 2014: 89).

Como en la Colombia de los noventa, la serie representa un Estado sobrepasado por el problema del narcotráfico:

- Las fuerzas de la ley se encuentran sometidas a los intereses de los criminales gracias a sobornos o amenazas. Esto se vislumbra en la cita ficticia de 'Plata o plomo' que Escobar dirige a los miembros de un control policial.

- La justicia no puede ejercer en libertad sus prerrogativas. Vemos como varios jueces deben tapar sus rostros para evitar represalias de los narcotraficantes, y Escobar financia el asalto al Palacio de Justicia de Bogotá, asesinando a miembros del tribunal supremo.

- Los medios de comunicación tampoco escapan a la influencia de los narcos. Algunos periodistas se ven seducidos por el dinero o el encanto personal de los criminales, como es el caso de la amante de Escobar, Valeria Vélez (personaje ficticio basado en la periodista Virginia Vallejo). Cuando los medios no se dejan corromper y denuncian las actividades del narcotráfico es cuando se inician las acciones violentas contra estos. En las imágenes de archivo emitidas en la serie se comenta el atentado de Escobar contra la sede del periódico El Espectador.

- Narcoestado: Pablo Escobar llegó a convertirse en congresista, y toma represalias contra aquellos políticos que desvelan sus vínculos con el narcotráfico. El Cartel de Cali tiene contactos y amistades con altos cargos de la política colombiana, llegando incluso a financiar la campaña del presidente Ernesto Samper.

- Narcoterrorismo: en su periplo por acabar con la extradición el cartel de Medellín no vacila en atentar contra las fuerzas del orden, la clase política e incluso la población civil. Algunos de sus ataques más sonados fueron los atentados al avión de Avianca el 27 de noviembre de 1989 (110 muertos) y el perpetrado en Bogotá del 30 de enero de 1993 (25 muertos y 70 heridos). En total, se atribuyen a la organización de Escobar un total de 623 atentados con casi mil muertos entre civiles y policías ${ }^{4}$. El uso de bombas como método de terror por parte del Cartel de Medellín se debe en gran parte a los contactos que mantuvo dicha organización con un miembro de la banda terrorista ETA (Villarreal, 2010: 62), hecho que se alude en la serie a través

4 'Las cifras del Mal' en Semana (Edición Digital), 2013. 
de un personaje ficticio llamado Efrán González, alias 'El Español' (basado en un miembro real no identificado de la banda apodado 'Miguelito') ${ }^{5}$.

- Otras violencias (secuestros, paramilitarismo y guerrillas): En esta época existieron en Colombia numerosos grupos armados con diferentes objetivos, pero que guardaron alguna relación con el narcotráfico. A las Fuerzas Armadas Revolucionarias de Colombia (FARC) se le sumaban grupos como el M-19, pionero en la utilización del secuestro como herramienta de presión para conseguir recursos económicos o influir decisiones políticas. Cuando en 1981 el M-19, guerrilla comunista, decidió secuestrar a Marta Nieves Ochoa, hermana del Clan Ochoa, asociado al Cartel de Medellín, Escobar reaccionó creando el grupo paramilitar 'Muerte a Secuestradores' (MAS), encargado de perseguir a los miembros del M-19. El MAS, si bien no fue el origen del paramilitarismo en Colombia, si que cimentó la aparición de futuros grupos como 'Los Extraditables', los 'Autodefensas Armadas de Colombia' o 'Los Pepes' (Sánchez G [coord.], 2013, páginas 29-30). Todos estos grupos cometieron actos que vulneraron sin pudor los derechos humanos, en muchas ocasiones amparados por la $\mathrm{CIA}$ y el propio Estado colombiano. Cuando el Cartel de Medellín se percata de que los ataques a la población civil son insuficientes para frenar la extradición, Escobar y su organización planean secuestrar a miembros de las familias más influyentes de Colombia. El asesinato de Ofelia Hernández disparó las alarmas de los familiares de los secuestrados, quienes presionaron al presidente Gaviria para que derogue la extradición. La muerte de la periodista Diana Turbayb, hija del ex presidente Julio César Turbay que fue asesinada accidentalmente en un fallido operativo de rescate, provoca que Gaviria termine por someterse a las presiones de los narcotraficantes, teniendo que dar marcha atrás con la extradición y cumpliendo el objetivo de los llamados 'Extraditables'7. Así, consiguió que Escobar finalmente se entregase, pero a cambio de permitirle construir su propia cárcel, que sería conocida como 'La Catedral's.

- Guerra Sucia: en la serie se refleja como el presidente Gaviria y su gabinete, obsesionados en acabar con Escobar, acometen actos de auténtica guerra sucia al no condenar los asesinatos perpetrados por los Pepes (incluso contra población civil, como en el asesinato de Valeria Vélez) o presionando a otros gobiernos a no dar asilo a la familia del capo medellinense como medida de presión contra el jefe criminal, aun a riesgo de que fuesen asesinados por los enemigos del cartel de Medellín. La configuración del llamado Bloque de Búsqueda, liderado inicialmente por el ficticio coronel Horacio Carillo muestra toda la crudeza e inmoralidad del Estado colombiano en su lucha contra los narcos: Carillo no duda en asaltar locales nocturnos en los que se encuentren soldados de Escobar, aun a riesgo de herir o asesinar a ciudadanos inocentes, como en la redada en la que asesinan al sicario Poison; tampoco vacila en asesinar a sangre fría a un adolescente informante del cartel para enviar un mensaje al resto de niños de los barrios pobres de Medellín de

5 Los contactos del Cartel de Medellín con dicho terrorista se conocen exclusivamente por los testimonios en entrevistas del ex sicario de Escobar Jairo Jhon Vazquez alias Popeye. Una de ellas es la que realizó al portal HispanoPost.

6 'La muerte de Diana Turbay, duro revés en la lucha contra los 'narcos' colombianos en El País, 1991.

7 'Fin de la extradición: 51 a favor, 13 en contra' en El Tiempo, 1991.

8 'Pablo Escobar se entrega al Gobierno colombiano' en El País, 1991. 
lo que les pasaría si estaban dispuestos a trabajar para los narcotraficantes. El grado del odio del Estado y las fuerzas del orden contra el cartel se ejemplifica cuando, tras el asesinato del abogado de Escobar Fernando Duque y su hijo a manos de los Pepes, el agente Trujillo, lejos de sentir pena (pese a que eran personas inocentes) responde que "muchos perdieron familiares a manos de Escobar"9.

Con la muerte del capo medellinense y con la llegada de Samper al poder se pone en marcha el llamado programa CONVIVIR, destinado a fomentar los ejércitos privados para luchar contra las guerrillas comunistas, señaladas no sólo como elemento de inestabilidad político-militar, sino también como principales responsables del narcotráfico ${ }^{10}$. En el aparato de guerra sucia participan funcionarios estadounidenses como el embajador norteamericano Arthur Crossby, quien no condena los actos del gobierno colombiano, sino que mas bien apoya los operativos; el teniente Lou, militar anticomunista encargado de dirigir las operaciones de inteligencia contra las guerrillas marxistas; el agente de la CIA Stechner, quien colabora con diversos grupos paramilitares para perseguir y exterminar enclaves de la guerrilla, cuyos 'soldados' en la mayoría de los casos no son más que campesinos desarmados, llegando incluso a preparar montajes para convencer a la opinión pública de que la guerra contra las drogas y la guerrilla realmente está siendo efectiva. Todos estos elementos inciden en la estrategia estadounidense en América Latina, justificada desde la caída del bloque soviético con la lucha contra el narcotráfico (Suárez, 2010: 6). La ClA suministra armamento a los Autodefensas, y el agente Peña colabora con Don Berna, entregándole información a los Pepes acerca del cartel de Medellín.

\section{PERSPECTIVA DE CLASE: DEL 'ROBIN HOOD PAISA' A LOS 'CABALLEROS DE CALI’}

A lo largo de la serie se incide mucho en la mentalidad y conciencia de clase de los dos grandes capos de la droga, las cuales difieren en muchos puntos.

El Pablo Escobar que encarna Moura tiene muchos puntos en común con el personaje real. Efectivamente, 'El Patrón' se crió en una familia campesina en Rionegro, pero no pertenecía a un grupo social excluido, sino que se crió en un barrio de clase media (La Paz de Envigado), teniendo una educación secundaria. Sus acercamientos al mundo del crimen, por tanto, no se explican en unos orígenes difíciles, sino en su acercamiento a personalidades del mundo del crimen y en concreto al negocio del contrabando, en alza en la zona de Antioquia. Convencido de que su verdadero papel en la vida era llegar a ser presidente de la República de Colombia para arrebatar el poder a los 'hombres de siempre', Escobar decide emprender una tristemente célebre campaña política. Se considera a sí mismo un hombre del pueblo, utilizando durante su campaña política para ser suplente en el Congreso discursos de carácter populista. Utilizó además el dinero del narcotráfico para construir un barrio para los habitantes de Moravia, canchas de fútbol, repartir mercados, abrir sitios de atención material, etc. El objetivo era, en realidad, construir redes clientelares con las que conseguir votos y la colaboración de la población para proteger sus actividades criminales y posteriormente ocultarse de las autoridades cuando se ordenó su detención (Duncan, 2013: 247-251).

9 El asesinato del abogado de Escobar y su hijo fue un episodio real, siendo el verdadero nombre de este Guido Parra Montoya. Esta noticia fue recogida por el periódico El Tiempo.

10 'Así nacieron las CONVIVIR' en El Tiempo, 1997 
La otra cara de la moneda la representan los jefes del cartel caleño, quienes se llaman a sí mismos Caballeros de Cali. Su modus operandi dista, en apariencia, de la violencia indiscriminada de Escobar, encomendándose al anonimato público y a la relación con la alta sociedad local. Jorge Salcedo, el jefe de seguridad de los hermanos Rodríguez, ordena a todos sus empleados que vayan desarmados, ya que consideran que la comunicación y la recopilación de información es lo verdaderamente importante a la hora de evadir a las autoridades, aunque paradójicamente acabaría delatando a uno de sus jefes ${ }^{11}$. Los hermanos Rodríguez se codean con la clase política y las clases adineradas, como bien se puede apreciar en la fiesta que organiza Gilberto para anunciar la salida del cartel del negocio de la droga. En dicha fiesta podemos ver entre los asistentes a varios tenientes de la policía de Cali e incluso al mismísimo alcalde de la ciudad. Pese al bajo perfil que intentan mantener, los capos de Cali no están exentos de participar en actos de extrema violencia, como por ejemplo el coche-bomba que ordenaron hacer estallar contra el edificio Mónaco en el año 1988. La cara más violenta del Cartel, en la ficción, la encarnan Pacho Herrera y Chepe Santacruz, quienes no escatiman en sádicos métodos para acabar con sus enemigos. El primero no duda en exterminar a toda la familia Salazar, mientras que el segundo no vacila en iniciar un tiroteo en pleno Manhattan ni en asesinar a sangre fría a un periodista cubano (basado en el periodista real Juan de Dios Unaune, quien no fue asesinado por Santacruz en persona, si no por un sicario contratado por este) ${ }^{12}$.

\section{NARCOCULTURA Y RELIGIÓN}

Colombia es un país eminentemente católico y la fuerza de la religión está presente a lo largo de toda la serie e imbuye con fuerza a muchos de sus personajes. Aludimos nuevamente al sincretismo o idolatría a la figura de Pablo Escobar, de quien se realizan numerosas representaciones como Jesucristo. Pacho Herrera es representado como una persona profundamente religiosa, y le vemos santiguarse al entrar en una iglesia local tras cometer un atentado e incluso escoge una capilla como lugar en el que entregarse a las autoridades. Por otra parte, tenemos al incorruptible general José Serrano, hombre profundamente religioso que decidió unirse a las fuerzas de seguridad del Estado tras toparse con unos agentes de la policía montada, quienes le recordaron a los guerreros santos de los Evangelios.

A lo largo de estas décadas aparecen numerosos narcotraficantes que han asumido diferentes roles de liderazgo en los que se entremezcla la leyenda y el mito, con diferentes alcances y dimensiones, quienes se han convertido en personalidades aplaudidas, envidiadas admiradas desde el imaginario colectivo, a lo que se suma una cierta aura martirizante como consecuencia de su encarcelamiento y asesinato. Estas personalidades del mundo del crimen han conseguido en algunos casos gran repercusión mediática gracias a la globalización, convirtiéndose en auténticos héroes o antihéroes entre algunos de los habitantes de sus poblaciones de origen, en las que perviven creencias y mitologías sobre supuestas bondades, aventuras y hazañas (Córdova Solís, 2012: 216). Sobre Escobar ha pervivido el mito de su figura en Medellín, en especial entre quienes habitan los barrios construidos por el capo criminal, lo que se pudo comprobar en la masiva asistencia a su funeral' ${ }^{13}$. A lo largo de

11 'Delatar si paga' en Semana, 1997

12 El diario El País se hizo eco del homicidio en su edición impresa del 13 de marzo de 1992.

13 'Precipitado entierro en Medellín del narcotraficante Escobar' en El País, 1993 
los diferentes capítulos de la serie podemos ver las ya mencionadas representaciones de Escobar como Jesucristo, murales con su figura, un barrio con su nombre... incluso es reconocido por una multitud de medellinenses que le rodean y agasajan cuando en ese momento era el fugado más buscado del mundo. El culto a su figura también se refleja en el personaje de Limón, joven criado en uno de los barrios que construyó Escobar y que no duda en introducirse en el mundo criminal para ayudar al capo, acompañándole hasta el momento mismo de su muerte.

En las dos primeras temporadas se hace alusión al realismo mágico y a su nacimiento en Colombia. En las obras de realismo mágico no hay distinción entre lo natural y lo sobrenatural. Lo real y lo irreal conviven sin que esto suponga un problema para los protagonistas y para la trama. La simbiosis entre Cine e Historia cobra mayor relevancia en el caso del Realismo Mágico, ya que posibilita la incorporación de lo que se conoce como intrahistoria, es decir, historias de vida, de las mentalidades, de los nadies, de todo aquello menospreciado por la historia oficial. Con todo, el término Realismo Mágico siempre ha suscitado controversia en el mundo audiovisual, y hay autores que consideran que debería limitarse a la literatura (Cascón Becerra, 2006: 119). Si bien el Realismo Mágico no es un elemento del que se haga demasiado uso en la ficción de Brancato, hay una escena en el que está presente con claridad: la conversación de Pablo y Gustavo en Medellín en las horas finales de Escobar. El primo del capo había sido asesinado por Carrillo y sus hombres, pero aún así se sienta al lado de Escobar en una parque y conversa con él sobre su disposición de entregarse o no a la justicia colombiana.

\section{LAS VÍCTIMAS, LA JUSTICIA Y LA MOVILIZACIÓN SOCIAL}

En medio de la guerra que mantuvo el Estado colombiano contra los carteles de la droga se produjeron numerosas víctimas. La violencia indiscriminada del cartel de Medellín atacó a todos los estamentos de la sociedad colombiana: civiles, fuerzas del orden, políticos, periodistas... Entre los asesinatos más sonados la ficción recoge los atentados mortales contra Rodrigo Lara Bonilla y Luis Carlos Galán.

Numerosos niños quedan huérfanos a consecuencia de las matanzas. Entre ellos la hija de 'Jaimito', el joven engañado por el cartel para hacer estallar la bomba del avión de Avianca, o la hija de Maritza, la amiga de Limón, asesinada por este último.

Dentro del mecanismo de guerra sucia, el fiscal general de Greiff es el único que busca mantenerse en la legalidad a la hora de afrontar la lucha contra el cartel. Desoyendo las instrucciones del presidente Gaviria de no mantener contacto alguno con Escobar, de Greiff ofrece al capo la posibilidad de volver a entregarse tras su fuga de La Catedral, y es quien ofrece protección a la familia Escobar tras no poder entrar en Alemania.

La sociedad, al principio, se moviliza pacíficamente contra el narcotráfico tras el asesinato de Bonilla, pero tras el atentando mortal contra Galán las manifestaciones contra los narcos se vuelven mucho más combativas. Escobar cuenta con gran apoyo en Medellín, "una ciudad que nunca le delataría", pero dicho apoyo empieza a decrecer como consecuencia de los violentos atentados en los últimos años de vida del Patrón, siendo el perpetrado el 30 de enero de 1993 el que pone a la sociedad colombiana en pie de guerra contra Escobar. Ya en tiempos del presidente Samper, el llamado Proceso 8000 moviliza a la sociedad colombiana contra un gobierno que había recibido dinero del cartel de Cali, y es la presión social la que acaba con la impunidad de los capos de los Caballeros. 


\section{NARCOECONOMÍA}

En los diversos episodios, y en especial cuando se recrudece la guerra podemos ver como los sicarios de Escobar utilizan su dinero e influencia en las calles para impulsar su economía de guerra. Las redes clientelares que crea el narcotráfico articulan toda una narcoeconomía en la que participan los habitantes de Medellín, desde los jóvenes de las calles (que trabajan como informantes o soldados del cartel), pasando por policías y políticos corruptos, periodistas, etc.

El flujo de dinero negro del Cartel de Cali funciona a través de un complejo sistema de blanqueo coordinado por Franklin Jurado, el cual regresa a manos como dinero legal a manos del cartel, siendo administrado por Enrique Pallomari contable jefe del cartel, quien distribuye el dinero de los sobornos a las autoridades.

También se insiste en el papel de guerrillas como las FARC en el negocio del narcotráfico, que financian su guerra contra el Estado gracias a la producción de cocaína, pero también con su participación y colaboración en diferentes operativos como el ataque al Palacio de Justicia por parte del MI9 o la retención de la esposa de Franklin Jurado por parte de una comuna campesina simpatizante de las FARC.

\section{MODELOS DE MASCULINIDAD Y FEMINIDAD}

El mundo de la serie Narcos es uno esencialmente masculino, aunque las mujeres tienen también su espacio, si bien es cierto que en papeles casi siempre secundarios cuyo único fin es complementar el desarrollo de los protagonistas masculinos. Se nos presentan algunas mujeres que ocupan posiciones de peso como es el de la narcotraficante Helga Salazar, aunque su protagonismo en pantalla se ve reducido por personajes masculinos que las apartan fuera de los primeros planos de la trama salvo en contados tramos. El personaje de María Salazar, viuda de Claudio Salazar, viene a encarnar el clásico papel de mujer fatal, manteniendo a conveniencia relaciones íntimas con diferentes narcos caleños, destacando su relación con Miguel Rodríguez. Maritza representa la cara opuesta de la moneda: mujer de clase popular, madre trabajadora y recelosa de entrar en el círculo de los narcotraficantes. Por otra parte, tenemos a Connie Murphy, cuya función es brindar apoyo moral para su marido, si bien es cierto que en ocasiones toma partido en la acción, como cuando ayuda a escapar a la guerrillera del M-19 Elisa Álvaro.

El personaje que mejor representa el modelo de masculinidad hegemónica es el propio Escobar. Se considera a sí mismo un hombre fuerte, inteligente y de un carisma excepcional, capaz de doblegar la voluntad de hombres y mujeres para que cumplan sus designios, ya sea mediante la diplomacia o la violencia. Las mujeres son una parte importante de su vida, empezando por su esposa Tata, siguiendo por su madre Hermilda y terminando por su amante Valeria Vélez. Cada una de ellas desempeña un papel diferente en la vida del narcotraficante. Su mujer cumple el papel de madre y esposa, el eje en torno al que se configura la vida familiar de Escobar, mientras que su madre representa evidentemente el papel materno, pudiendo penetrar en las emociones de Pablo a un nivel que ninguna otra persona puede. Valeria Vélez con el tiempo se acaba convirtiendo en un importante apoyo mediático y emociona, y a su vez la periodista desarrolla también un fuerte sentimiento por Escobar. 
Si hay dos personajes que mejor encarnan la inmoralidad y el machismo más acentuado son los de La Quica y David Rodríguez. Ambos desempeñan la función de sicarios principales de sus respectivos patrones (Escobar y Miguel), y no dudan en utilizar la violencia más cruda las veces que haga para conseguir sus objetivos. La visión utilitaria de la Quica sobre las mujeres de Medellín se observa en el momento que acosa con un vocabulario soez a Maritza en el taxi para que mantenga relaciones sexuales con él.

\section{CONCLUSIONES}

Como toda ficción televisiva, Narcos se toma numerosas licencias artísticas a la hora de reflejar una de las épocas más duras de la historia de Colombia. La representación misma de sanguinarios traficantes como Pablo Escobar o Gacha incluso se antoja en ocasiones excesivamente caricaturizada. La participación de Javier Peña en el desmantelamiento del cartel caleño es también ficticia, ya que el agente abandonó Colombia seis meses más tarde de la muerte de Escobar, por lo que no llegó a participar en el arresto de los padrinos de Cali.

Pese a sus fallos, la serie consigue tocar, ligeramente, algunos temas interesantes. Entre ellos, plantea si todo vale en la lucha contra el narcotráfico, saltándose el respeto a los derechos humanos e involucrando a víctimas inocentes en la guerra contra los carteles. Lamentablemente, estos aspectos acaban por no desarrollarse en detrimento de la acción y la violencia.

En definitiva, la ficción de Netflix presenta una Colombia dividida, sumida en un conflicto interno en el que dos bandos se enfrentan mientras el pueblo adolece en medio de la violencia indiscriminada. Pero quizá falla en el mismo punto que otras ficciones sobre narcotráfico: la versión excesivamente romántica que presenta de Pablo Escobar y otros capos criminales, llegando a banalizar en determinados momentos los acontecimientos que busca relatar. Pese al supuesto atractivo que pueda desprender la historia de El Patrón, en una sociedad democrática no puede caber otra cosa que la repulsa a su figura, ya que no podemos olvidar que Escobar y sus ejércitos criminales sumieron a Colombia en sus años más oscuros, sembrando el miedo entre la población y dejando un reguero incontable de asesinados, heridos, huérfanos y familias destrozadas. La otra cara de la moneda la protagoniza el gabinete de Gaviria, que desplegó un mecanismo de guerra sucia que resultó a todas luces inefectivo, ya que, si bien dejar operar libremente a los Pepes permitió acabar con el Cartel de Medellín, el precio fue permitir el asesinato de inocentes y el auge del Cartel de Cali.

Al final, Narcos refleja Colombia como un Estado semi-fallido, incapaz de resolver sus asuntos internos, bajo constante tutela norteamericana y sin posibilidad aparente de ir a mejor. Estados Unidos y los agentes de la DEA son como una especie de padre que intenta llevar a su hijo por el buen camino, mientras que el gobierno colombiano se aproxima más a esa especie de hijo adolescente rebelde que recuerda una y otra vez a los agentes de la DEA que pueden resolver sus propios asuntos, aunque al final siempre son los norteamericanos quienes salvan el día. En ocasiones se intenta alguna crítica a la política intervencionista norteamericana, a la hipocresía y a los intereses oscuros de la ayuda estadounidense, pero no dejan de ser criticas muy ambiguas, que se ven opacadas por un mensaje final bastante conservador. 


\section{BIBLIOGRAFÍA CITADA}

AA. V., Una sociedad secuestrada, Bogotá, Centro Nacional de Memoria Histórica, 2013.

Ávila Martínez, A. \& Bernardo Pérez Salazar, Mercado de criminalidad en Bogotá, Bogotá, Corporación Nuevo Arco Iris, 2011.

Cadena Montenegro, J. L., «Geopolítica del narcotráfico. México y Colombia: la equivocación en el empleo de las fuerzas militares», Revista Mexicana de Ciencias Políticas y Sociales, 210 (2010), pp. 45-58.

Cascón Becerra, J. A., "Realismo mágico. Historia e intrahistoria en el cine iberoamericano», Trocadero, 18 (2006), pp. 113-116.

Córdova Solís, N., «La Narcocultura: poder, realidad, iconografía y "mito"», Cultura y representaciones sociales, 12 (2012), pp. 209-237.

Di John, J., "Conceptualización de las causas y consecuencias de los Estado Fallidos: una reseña crítica», Revista de Estudios Sociales, 37 (2010), pp. 46-86.

Duncan, G., «Una lectura política de Pablo Escobar», Co-herencia Revista de Humanidades, 19 (2013), pp. 235-262.

Fernández Cruz, M., «Escobar, el patrón de mal: las claves del éxito de la serie del momento», La Nación, 23 de enero de 2014; <https://www.lanacion.com.ar/1657577-escobar-elpatron-de-mal-las-claves-del-exito-de-la-serie-del-momento> [consulta: 03 mayo 2018].

García, M. I., «Precipitado entierro en Medellín del narcotraficante Escobar», El País, 4 de diciembre de 1993; <https://elpais.com/diario/1993/12/04/ internacional/754959619_850215.html> [consulta: 10 mayo 2018].

Legarda Martínez, A., El verdadero Pablo: Sangre, Traición y Muerte, Bogotá, Dipon, 2005. López Zuleta, D., «Popeye: Un terrorista de ETA enseñó a fabricar bombas a Pablo Escobar», HispanoPost, 27 de julio de 2016; <http://www.hispanopost.com/popeye-un-terroristade-eta-enseno-a-fabricar-bombas-a-pablo-escobar> [consulta: 08 mayo 2018].

Lozano, P., «La muerte de Diana Turbay, duro revés en la lucha contra los 'narcos' colombianos», El País, 27 de enero de 1991; <https://www.google.es/amp/s/elpais. com/diario/1991/01/27/internacional/664930808_850215.amp.html> [consulta: 09 mayo 2018].

Lozano, P., «Pablo Escobar se entrega al Gobierno colombiano», El País, 20 de junio de 1991; <https://elpais.com/diario/1991/06/20/internacional/677368825_850215.html> [consulta: 09 mayo 2018].

Pontón C, D. \& Fredy Rivera Vélez, El ascenso estratégico: lógicas y despliegues del crimen organizado en Ecuador, Quito, Flacso, 2011.

Pontón C, D., "La economía del narcotráfico y su dinámica en América Latina», Iconos. Revista de Ciencias Sociales, 47 (2013), pp. 135-153.

Reuters, «Periodista asesinado», El País, 13 de marzo de 1992; <https://elpais.com/ diario/1992/03/13/internacional/700441209_850215.html> [consulta: 10 mayo 2018].

Sevilla Soler, R., "El café y la cocaína como motores de la economía colombiana», en María Justina Sarabia Viejo (coord.), Europa e Iberoamérica, Cinco Siglos de Intercambio, II, Sevilla, Asociación de Historiadores Latinoamericanistas Europeos, 1992, pp. 725-742.

Suárez, H., Intervenciones de Estados Unidos en América Latina, Londres, Manifiesto Press, 2010 . 
Torres, E., «Fin de la Extradición: 51 a favor, 13 en contra», El Tiempo, 20 de junio de 1991; <http://m.eltiempo.com/archivo/documento/MAM-107027> [Fecha de consulta: 09 mayo 2018].

Vargas Llosa, M., «El Patrón del Mal», El País, 25 de agosto de 2013; <https://elpais.com/ elpais/2013/08/22/opinion/1377179779_669163.html> [consulta: 03 mayo 2018].

Villarreal Sandoval, E., El Estado mexicano ante el fenómeno jurídico-social del narcoterrorismo, UNLA, 2007.

Zapata Callejas, J.S., «La teoría del Estado Fallido: entre aproximaciones y disensos», Revistas de Relaciones Internacionales. Estrategia y Seguridad, 1 (2014), pp. 87-110. 